Bijdragen tot de Dierkunde, 50 (2): $342-350-1980$

\title{
ON DUGESIA GONOCEPHALA FROM WESTERN EUROPE
}

\author{
by \\ FLIZABETH J. DE VRIES \& IAN R. BALL \\ Institute of Taxonomic Zoology, University of Amsterdam, The Netherlands
}

\begin{abstract}
Dugesia gonocephala s.l. is often considered to be a "superspecies" comprising numerous component "microspecies" which are morphologically, karyologically, and reproductively delimited. We have studied populations of $D$. gonocephala from France, Belgium and The Netherlands and found them to be fairly uniform in respect of most features studied. Nevertheless, discrepancies between them and the "classical" concept of this species as embodied in the literature have raised doubts as to the status and identity of $D$. gonocephala s. str. A proper understanding of the relationships of the D. gonocepbala group can not be obtained without resolution of this problem.
\end{abstract}

\section{INTRODUCTION}

This study is a development of faunistic work on the freshwater triclads of the dépt. Pas-de-Calais in northern France. During the course of that work problems arose concerning the identity and status of the locally occurring populations of $D u$ gesia gonocephala, for their anatomy seemed not to conform with the standard descriptions of that species in numerous papers and handbooks. Dugesia gonocephala, the type species of the genus, and of the family Dugesiidae (Ball, 1974), is a common and widespread freshwater triclad species in the Old World. Supposedly one of the best known of all freshwater planarians, the question of its status and taxonomy has always been a complex one.

According to Dahm (1958, 1967), Benazzi (1955) and Benazzi \& Benazzi-Lentati (1976) Dugesia gonocephala is to be thought of as a "superspecies" comprising numerous "microspecies" occurring in Europe, Asia and Africa, and which are reproductively isolated and morphologically differentiated with respect to the structure of the copulatory apparatus. As Dahm (1967) has pointed out, the natural relationships of the component populations are still difficult, and of ten impossible, to evaluate at present. But if this is to be achieved then it is necessary to have a clear knowledge of the structure of Dugesia gonocephala sensu stricto, and therein lies the problem.

Dugesia gonocephala was originally named and described by Dugès (1830), apparently from specimens collected in the general area of Montpellier, France. Only the external features were described and Schmidt (1860) was the first to study and describe the copulatory apparatus. His account was refined and amplified by Ude (1908) who redescribed the species on the basis of specimens from the vicinity of Graz, Austria. However, in this description Ude was in error concerning the position of the oviducts and this error was perpetuated in the classic works of Böhmig (1909), Steinmann \& Bresslau (1913) and Von Graff (1912-1917). The original slides of Ude were re-examined by Meixner (1928) who noted and corrected this significant error. Nevertheless, the error continued to appear in more recent publications, apparently on the assumption that, since $D$. gonocephala is so familiar a species, repetition of the older figures by Ude and Böhmig is sufficient (e.g. Den Hartog, 1962).

As will be seen the species is not so well known as is generally supposed. We have found it difficult to find specimens that correspond to the classical figures of Böhmig and Ude, particularly in respect of the morphology of the penis and male atrium, and notwithstanding the fact that both Stoppenbrink (1905, material from Bonn, W. Germany) and De Beauchamp (1961, unspecified material) appear to have done so. Consequently we have undertaken a more thorough analysis of several European populations of Dugesia gonocephala, not only in respect of the morphology of the copulatory apparatus, but also including histological and karyological data together with studies on the structure of the pharynx, all characters that have come to assume some importance in modern planarian taxonomy. 


\section{MATERIALS AND METHODS}

The newly collected specimens used in this study were obtained from the following localities:

FraNCE. - A small tributary of the river Slack, northwest of Réty, Pas-de-Calais. Collected by E. J. de Vries in October 1977 and October 1978.

Belgium. - Ruisseau de la Fontaine, near Lorcé, Harzé la Gleize, Ardennes. Collected by Hilde Veenstra, November 1978.

The Netherlands. - Small stream northeast of Vlodrop, Zuid-Limburg. Collected by B. Pex and E. J. de Vries, April 1979. - Small stream between the villages of Mechelen and Epen, Zuid-Limburg. Collected by B. Pex and E. J. de Vries, April 1979. - Spring near Broek, Epen, Zuid-Limburg. Collected by Ronald A. Gase, July 1979.

All these populations have been studied morphologically and karyologically according to the usual methods as given, for example, by Ball \& Gourbault (1975).

For comparative studies additional museum material, as serial sections, was examined, as follows:

France. - Dugesia gonocephala from the vicinity of Paris.
Part of the collections of the late Professor P. de Beauchamp now housed in the Muséum National d'Histoire Naturelle, no. 262, sagital sections on three slides, and no. 167 , sagittal sections on two slides.

ZarRe. - Dugesia gonocephala from the Parc National de l'Upemba. Part of the material described by Marcus (1953) and now housed in the collections of the Naturhistoriska Riksmuseet, Stockholm. No. 726 , sagittal sections on two slides, and no. 752, sagittal sections on two slides.

SoutherN EUROPE. - Several uncatalogued and undocumented slides of Dugesia benazzi, D. sicula, D. etrusca, $D$. monoadenodattila and $D$. ilvana loaned by Professor M. Benazzi, Istituto di Zoologia e Anatomia Comparata, Università di Pisa.

\section{RESULTS AND DISCUSSION}

Individuals from all of the populations studied had the typical shape, size and colour of Dugesia gonocepbala and all the populations were sexually reproducing. The general anatomy of the copula-

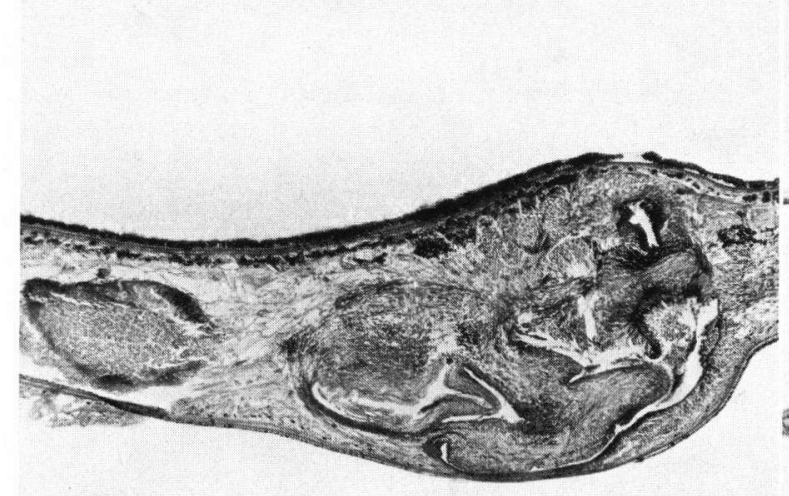

A
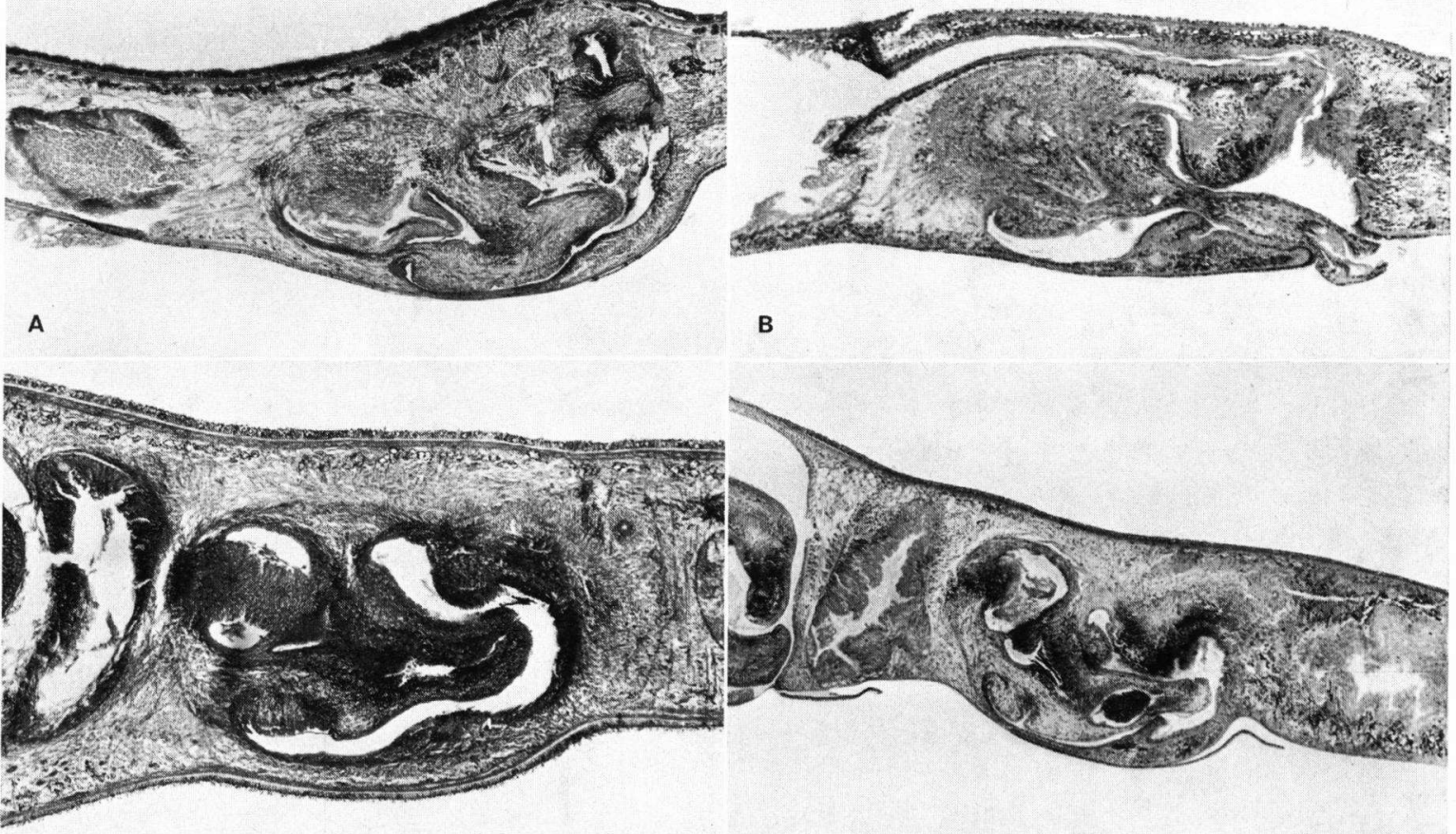

B

C

D

Fig. 1. Dugesia gonocephala, sagittal sections of the copulatory organs viewed from the left side. A, The Netherlands, $X 27$; B, northern France, $X 26.5$; C, Belgium, $X$ 53; D, Paris, France (De Beauchamp collection, no. 262 ), $\times 26$. 
tory apparatus was also similar in all the populations (figs. 1 and 2) but they differed from the classical descriptions of Ude (1908) and Böhmig (1909) in respect of three principal features, viz. (a) the anatomy of the penial papilla, (b) the form and musculature of the atrium, and (c) the histology of the bursal canal. These will be described and discussed in turn, followed by comments on (d) pharyngeal structure and (e) karyology.

(a) The penial papilla. - The penis is of the normal triclad construction with welldeveloped muscular bulb and elongate conical papilla (figs. 1 and 2). Within the bulb there is a cavity, the seminal vesicle, which is separated by a diaphragm from the ejaculatory duct which runs medially through the penial papilla to open at its tip. The most striking feature of the papilla is the strong fold, or invagination, at its base. At first sight this may be thought to be an artifact, comparable to that found in some specimens of Dugesia festai from Lake Titicaca which led Hyman (1939) to describe them, erroneously, as a new species (Hyman, 1951). But the fact that they are present in all the specimens sectioned, whatever the state of contraction or relaxation (figs. 1 and 2 ) and are to be seen also in some of the material of De Beauchamp from near Paris (fig. 3) convinces us that the fold is real. Certainly its distinctness is partly dependent upon the state of relaxation of the penis, but it is always present.

This penial fold seems not to have been described for any specimens of Dugesia gonocephala s.str.; it cannot be seen in any of the illustrations from the many papers already cited. Superficially it is similar to a condition found in some Oriental species described by Ball (1970) and Kawakatsu et al. (1976). But in Dugesia batuensis this fold is certainly of different origin because it is well developed in partially mature individuals in which the atrium has differentiated, but not yet the penis (Ball, 1970). Thus in this species the fold is truly a part of the atrial wall, whereas in our material of Dugesia gonocephala it is clearly a part of the penis itself.

The situation with Dugesia japonica is more complicated. This is a highly variable, polytypic, species (Kawakatsu et al., 1976), many populations of which show peculiarities of the penis/ atrium. The strong folds at the base of the penis clearly are considered by Kawakatsu et al. to belong to the penis and not to the atrium. Whether or not they are homologous with those here described for $D$. gonocephala can only be decided by developmental studies.

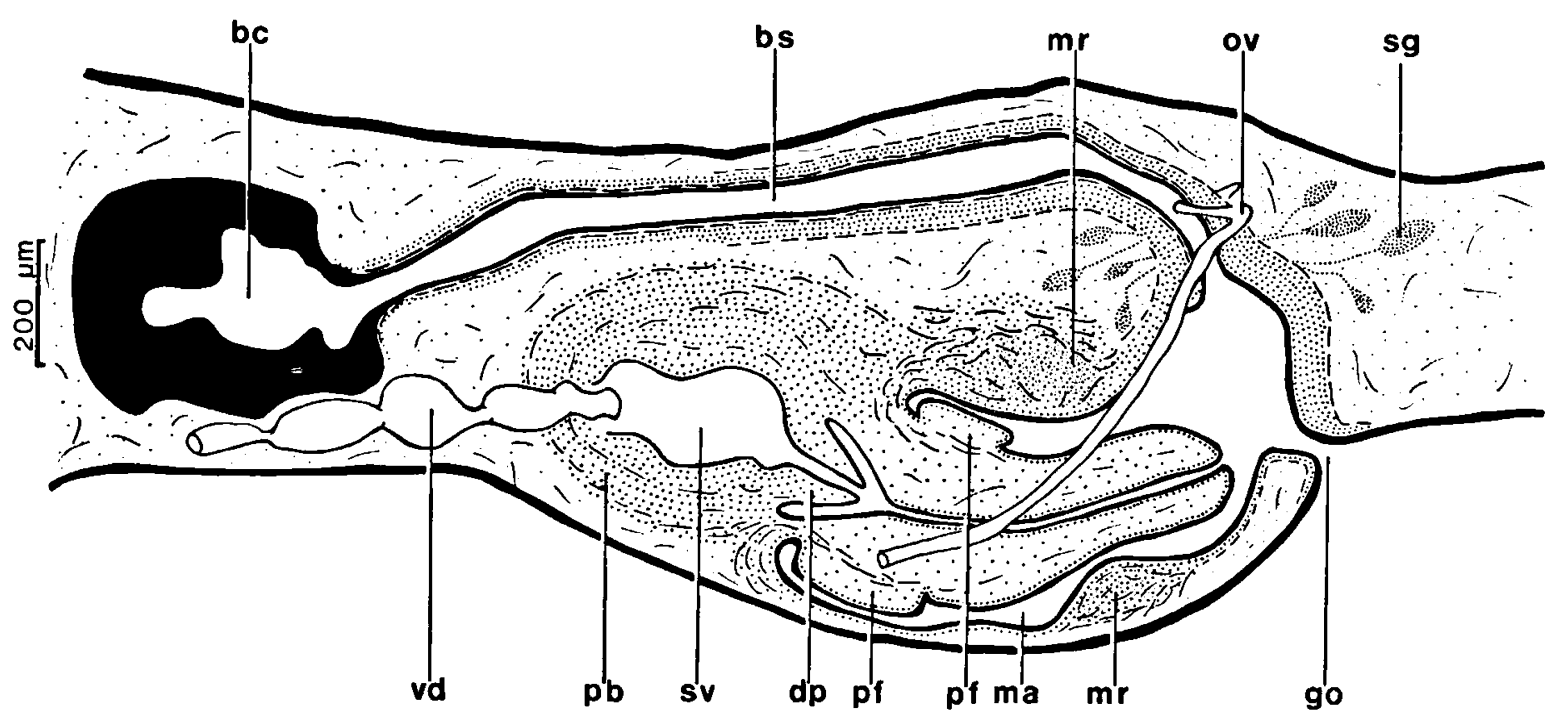

Fig. 2. Dugesia gonocephala, diagrammatic sagittal section of the copulatory organs viewed from the left side (cf. fig. 1A). Abbreviations: bc, bursa copulatrix; bs, bursal canal; dp, diaphragm; go, gonopore; ma, male atrium; mr, muscular ridge; ov, oviduct; pb, penis bulb; pf, penial fold; sg, shell glands; sv, seminal vesicle; vd, vas deferens. 


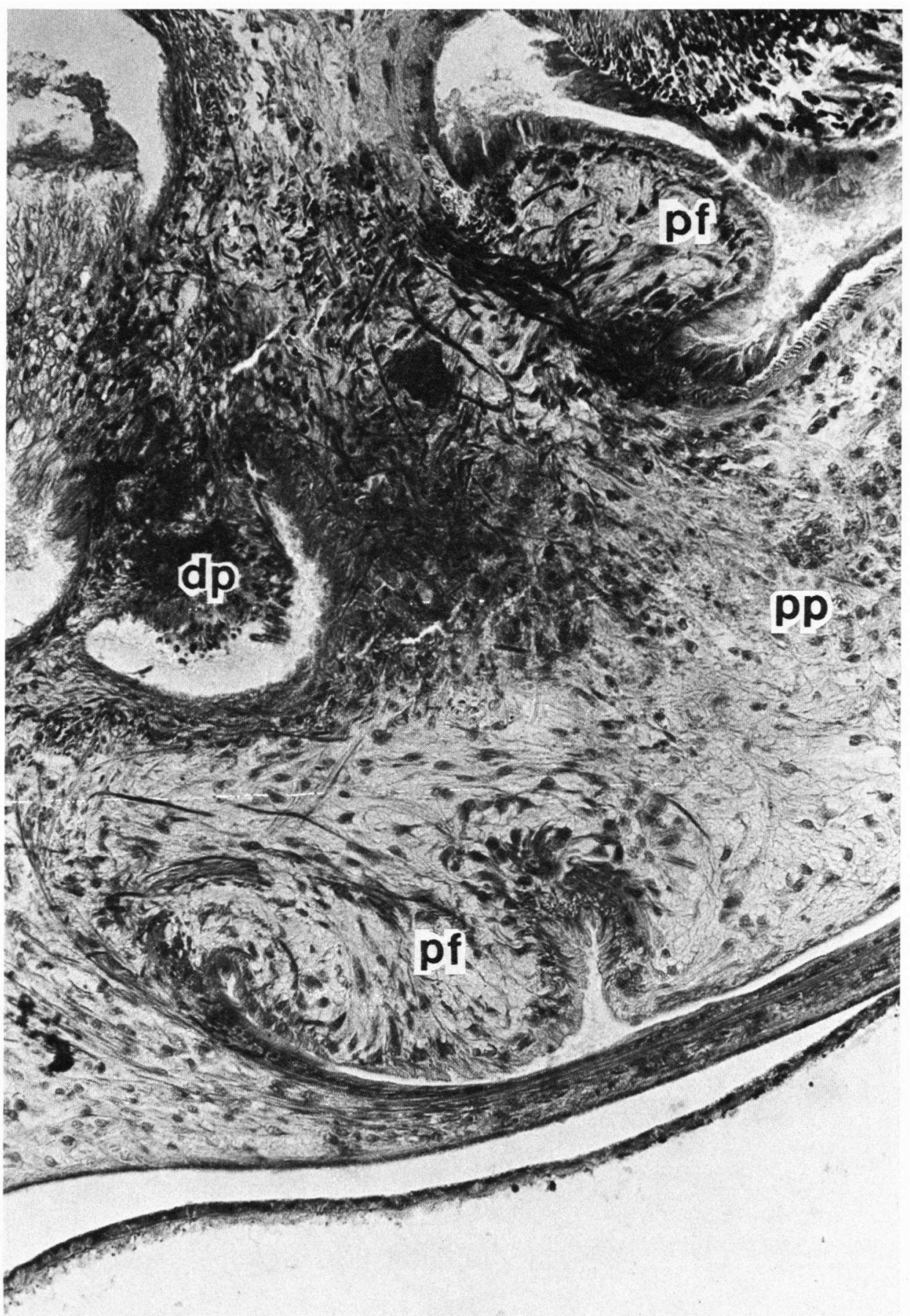

Fig. 3. Dugesia gonocephala (De Beauchamp collection, no. 262), sagittal section through the base of the penis papilla $\times$ 250. Abbreviations: dp, diaphragm; pf, penial fold; pp, penis papilla. 
(b) The at rium. - The atrium is the cavity which houses the penis, receives the openings of the female ducts, and opens to the exterior by a gonopore. According to Stoppenbrink (1905) the atrium of Dugesia gonocephala is lined with a ciliated epithelium but, in common with all other workers, we have always found cilia to be lacking. The characteristic atrial feature of the populations we have studied is its marked division by an annular muscular ridge into a male and a common atrium, the gonopore opening into the latter. This annular ridge is easily recognized by its highly developed circular and longitudinal musculature and by its glandular nature (figs. 1 and 2). Contraction of the circular muscles emphasizes the division of the atrium, whereas their relaxation will result in a wide opening between the male and common atria through which the penis can be extended during copulation.

Traditionally the atrium of $D$. gonocephala is described as being undivided (Ude, 1908; Dahm, 1958 ) in contradistinction to what we have found. Ude (1908) mentioned that Ijima (1887) had found a circular fold dividing the atrium but he himself had not observed it. Stoppenbrink (1905) also mentioned an atrial fold in his material although it is not really apparent in his figures. Variability of the atrium, perhaps caused by cocoon deposition, was reported by Marcus (1953) for his specimens from Zaire, but no true atrial fold was found in any of his material examined by us. Certain Mediterranean forms, viz. Dugesia ilvana and $D$. sicula, of the $D$. gonocephala group have been described as having a divided atrium (Lepori, 1951) but in these forms the point of division lacks the muscular and glandular specialization that we have observed, especially the strong annular musculature of the muscular ridge (figs. 1 and 2).

(c) The bursal can a l. - The musculature of the bursal canal of planarians has, in recent times, assumed considerable taxonomic importance. According to Ball (1974) the primitive condition in triclads is of a two-layered musculature continuing the sequence of the bodywall, and thus comprising inner circular and outer longitudinal fibres. In some of the Dugesiidae, however, the muscle layers have become reversed so that the longitudinal fibres form the immediately subepithelial layer. Such is the case in Dugesia gonocepbala.

Dugesia burmaensis (Kaburaki, 1918) and $D$. astrocheta Marcus, 1953, are unusual in that they possess a third continuous outer layer of longitudinal muscles extending the length of the bursal canal. In many of the other species of the superspecies such an extra layer of fibres is confined to the vaginal region of the canal and has been referred to by Ball (1974) as "ectal re-inforcement".

In most previous descriptions of Dugesia gonocephala s.str. such ectal re-inforcement has not been described. Nonetheless it is present in the French, Belgian and Dutch specimens studied here. Moreover, the extra-longitudinal fibres extend far beyond the vaginal region of the bursal canal, although they do not quite reach the bursa itself (fig. 2). Interestingly enough, Stoppenbrink (1905) described outer longitudinal fibres extending as far as the bursa. A similar extension is also known for some populations of Dugesia japonica (Kawakatsu et al., 1976), a species once confused with $D$. gonocephala.

The functional significance of the extra layer is not known and its evolutionary significance cannot adequately be assessed without further information on its geographic and taxonomic distribution.

Traditionally the epithelium of the bursal canal of Dugesia gonocephala has been described as nucleate (Meixner, 1928). Marcus (1953), however, suspected that in this species this character is as variable as it is in the New World Dugesia (Girardia) tigrina. Our findings confirm this opinion. In the Belgian material the epithelium of the bursal canal is indeed nucleate, but in all the French populations it is infranucleate. Both conditions were found in specimens from the Netherlands, even in fully mature individuals from the same population.

(d) The phary nx. - The outer musculature of the pharynx of aquatic triclads consists of two layers, an outer subepithelial layer of longitudinal fibres and an inner zone of circular fibres. Kenk (1930) drew attention to the fact that in Dugesia 


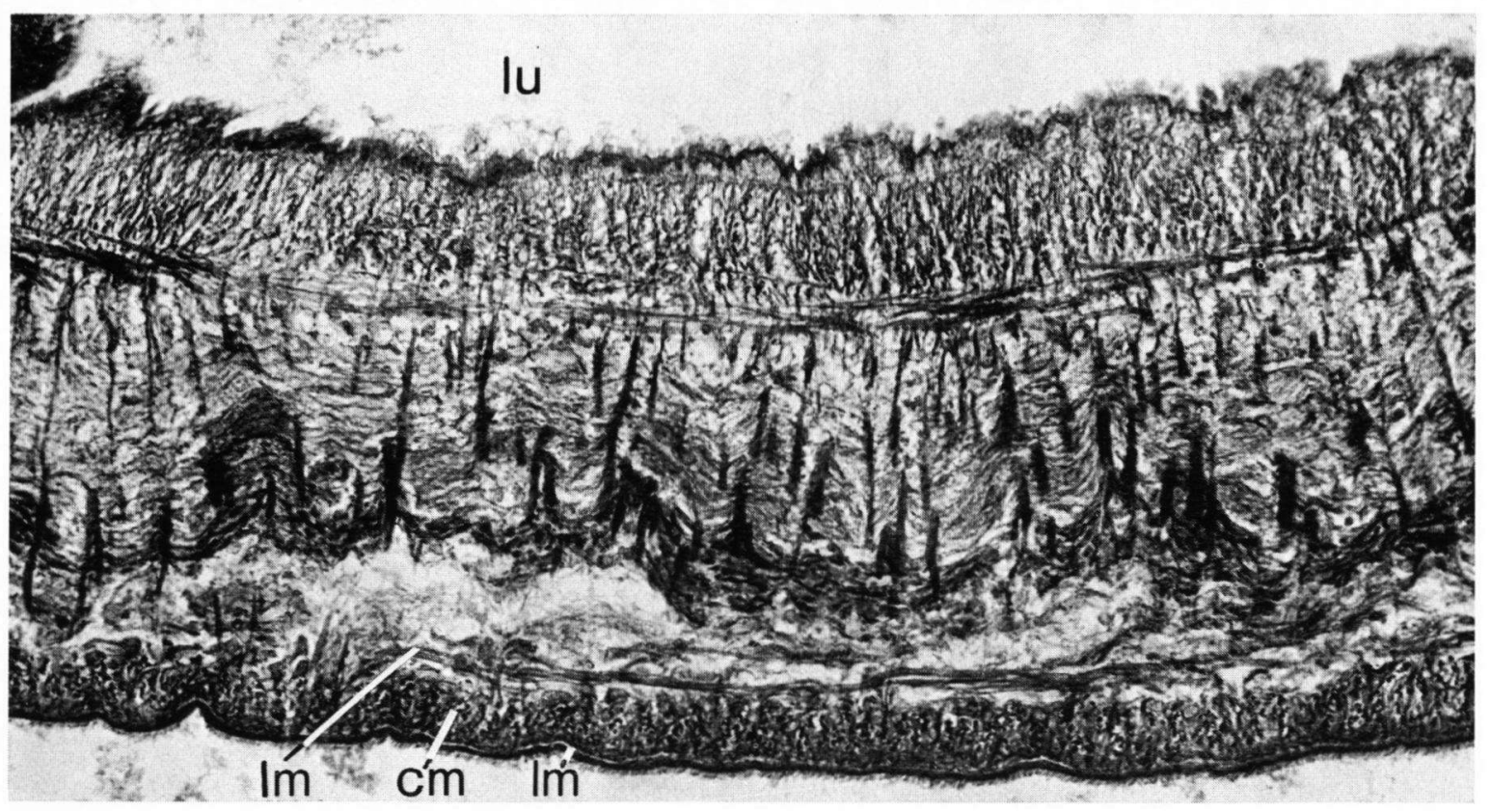

Fig. 4. Dugesia gonocephala, longitudinal section through the pharynx of a specimen from Zuid-Limburg, The Netherlands, $\times$ 270. Abbreviations: $\mathrm{cm}$, circular muscle; $\mathrm{lm}$, longitudinal muscle; lu, lumen of the pharynx.

gonocepbala there is a third layer, comprising longitudinal fibres, internally to the circular layer, which may be of taxonomic importance in delimiting $D$. gonocepbala s.str. from other members of the species group. Many subsequent workers have attached discriminatory significance to this character (Marcus, 1953, 1955; Dahm, 1967; Ball, 1970, 1974; Young \& Young, 1974), whereas De Beauchamp (e.g. 1936) always maintained that this feature is variable in $D$. gonocephala and is therefore not as valuable a taxonomic character as is sometimes thought.

Our own findings confirm De Beauchamp's opinion. Most individuals of the populations we studied possessed a recognizable third layer of longitudinal muscle fibres, but it could not be seen in all of them. In some individuals the third layer, although present, was rather diffuse and scattered, strong in some parts of the pharynx and weak or absent in others. This is particularly evident from fig. 4; the third layer disappears to the left of the picture. It is also noteworthy that in material we have examined from Corfu (cf. Ball, 1978) the third muscle layer is totally absent although in all other respects the material conforms to Dugesia gonocephala as we know it.

\section{TABLE I}

Relative lengths (r.l.) and centromeric indices (c.i.) with standard deviations, of the 8 chromosome pairs of Dugesia gonocephala from Belgium ( 6 plates $/ 4$ individuals), The Netherlands $(24 / 5)$ and France $(6 / 3)$.

\begin{tabular}{|c|c|c|c|c|c|c|}
\hline \multirow[t]{2}{*}{ Chromosome } & \multicolumn{2}{|c|}{ Belgium } & \multicolumn{2}{|c|}{ Netherlands } & \multicolumn{2}{|c|}{ France } \\
\hline & r.l. & c.i. & r.l. & c.i. & r.l. & c.i. \\
\hline 1 & $16.24 \pm 1.26$ & $43.55 \pm 2.68$ & $16.74 \pm 1.42$ & $45.26 \pm 3.69$ & $16.71 \pm 0.75$ & $45.05 \pm 2.22$ \\
\hline 2 & $14.45 \pm 0.78$ & $47.06 \pm 2.85$ & $14.35 \pm 0.96$ & $45.12 \pm 4.29$ & $13.69 \pm 0.68$ & $47.59 \pm 1.62$ \\
\hline 3 & $13.18 \pm 0.39$ & $45.87 \pm 2.72$ & $13.31 \pm 0.65$ & $45.36 \pm 3.71$ & $13.09 \pm 0.48$ & $47.74 \pm 1.45$ \\
\hline 4 & $12.41 \pm 0.77$ & $44.04 \pm 2.78$ & $12.33 \pm 0.62$ & $45.83 \pm 2.72$ & $12.06 \pm 0.72$ & $46.17 \pm 2.75$ \\
\hline 5 & $11.79 \pm 0.42$ & $44.33 \pm 3.13$ & $11.72 \pm 0.58$ & $46.06 \pm 3.91$ & $11.86 \pm 0.61$ & $43.25 \pm 2.56$ \\
\hline 6 & $11.02 \pm 0.49$ & $44.57 \pm 2.17$ & $11.17 \pm 0.52$ & $45.51 \pm 2.85$ & $11.18 \pm 0.27$ & $47.64 \pm 1.75$ \\
\hline 7 & $10.99 \pm 0.96$ & $47.95 \pm 2.08$ & $10.64 \pm 0.57$ & $43.96 \pm 3.45$ & $11.14 \pm 0.44$ & $45.58 \pm 3.34$ \\
\hline 8 & $9.97 \pm 0.49$ & $43.26 \pm 5.41$ & $9.91 \pm 0.81$ & $46.10 \pm 3.18$ & $10.48 \pm 0.56$ & $47.78 \pm 1.90$ \\
\hline
\end{tabular}


Thus we counsel caution in using the pharyngeal musculature as a character distinguishing $D u$ gesia gonocephala s.str. from its close relatives.

(e) Ka r y o log y. - Treatment of several speccimens from each of the five populations yielded many countable metaphase plates all comprising 16 chromosome pairs (fig. 5). Karyometric data for several of the most clear plates are given in table $I$. The chromosomes of all the populations decrease gradually in size, the largest size interval being between the first and second chromosome. The centromeric index is more variable, resulting sometimes in matching difficulties, and hence the high values for some of the standard deviations. However, in all cases the centromere is situated in the median region of the chromosome and thus they fall into the $m$ group (Levan et al., 1964), which is "metacentric" in the terminology of Benazzi \& Benazzi-Lentati (1976).

The karyology of the investigated populations is in accord with other published data on Dugesia gonocephala. It must be stated, however, that detailed comparison is not always easy since many authors do not give precise data concerning the relative lengths and centromeric indices of the chromosomes. The gradual decrease in length of the elements, and the variation in centromere position as described by Dahm $(1958,1963)$ and Benazzi \& Benazzi-Lentati (1976) are almost identical to those we have found. Dahm (1967) reported a "striking" difference between the first and second chromosomes of specimens from central Europe, but since he provided no exact numerical data it is difficult to know precisely how "striking" the difference he found actually is. Nevertheless our data are in accord with Dahm's findings. The data from Corfu are also similar with the exception that elements 3 and 5 have a much lower centromeric index (Ball, 1978).

Variation in chromosome morphology between the populations is not high, but it does occur. Therefore it seems that Dahm (1963) was premature in suggesting that European and Japanese members of the Dugesia gonocephala group could be separated by differences in the centromeric index of the fourth pair of chromosomes. More recently Kawakatsu et al. (1976) and Tamura et al. (1978) have presented data that may form a basis for distinguishing the European and Japanese species karyologically.

Although all the populations here studied were sexual diploids with a basic haploid number of $\mathbf{8}$, considerable variation may be found in members

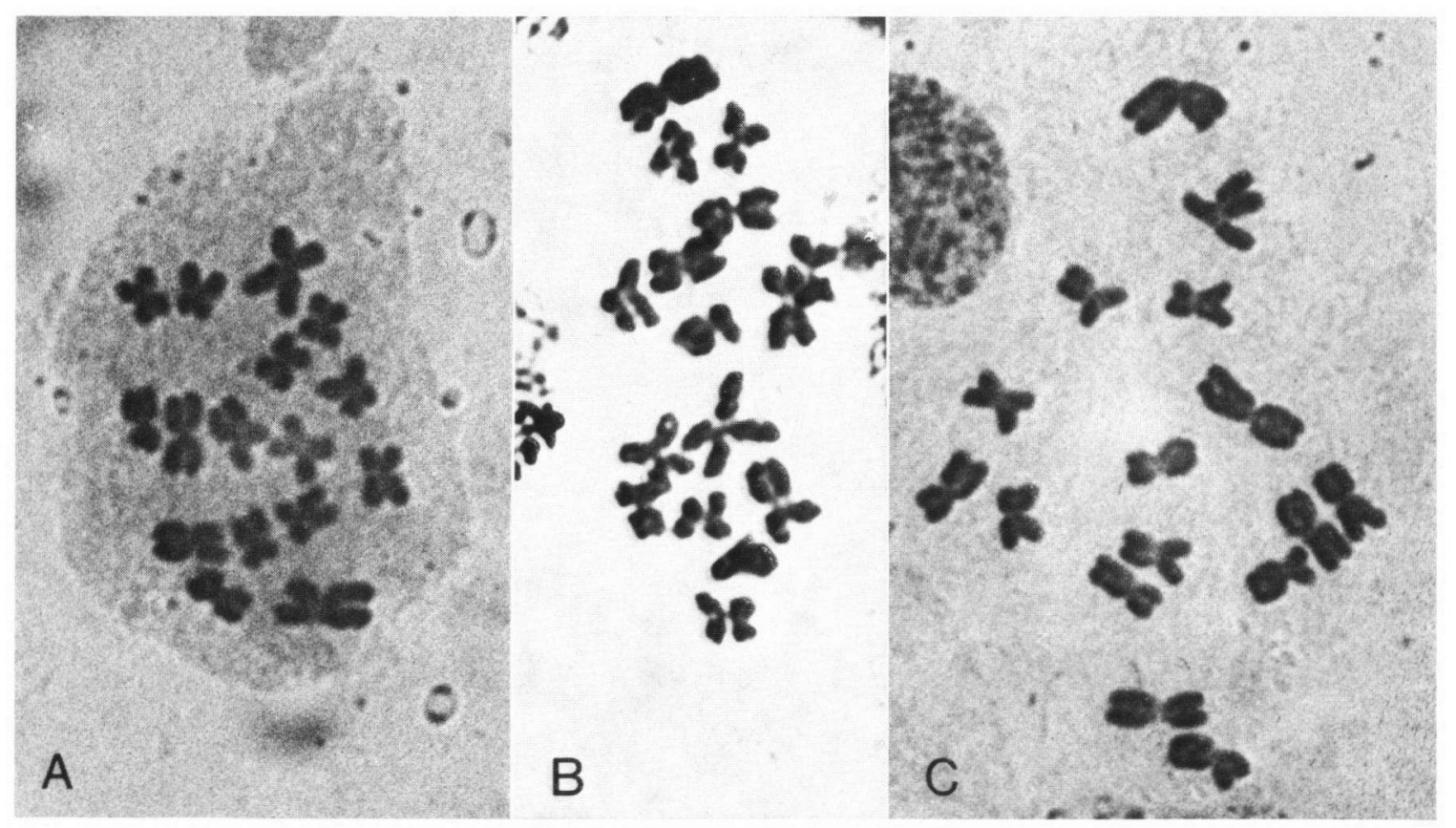

Fig. 5. Dugesia gonocepbala, metaphase plates, $2 \mathrm{n}=16 . \mathrm{A}$, northern France; B, Belgium; C, The Netherlands. 
of the species group. In some species the basic number is 9 (Benazzi, 1949; Bromley, 1974; Gourbalt \& Benazzi, 1979) and polyploidy and supernumerary chromosomes may occur. The apparent polymorphism of Dugesia gonocephala s.str. coupled with the relative uniformity of its karyotype is thus noteworthy.

\section{CONCLUSIONS}

We have demonstrated that the herein studied West-European populations of Dugesia gonocephala differ from the typical form, or at least the classic concept of the typical form, particularly in peculiarities of the morphology and histology of the copulatory apparatus. We have found these same "peculiarities" in material from Corfu, Greece and they seem also to be present in the figures of Dugesia gonocephala from Austria, Germany and Denmark given by Kawakatsu (1971: fig. 5; an English version of the Japanese legend is given in Kawakatsu, 1972: 63). It seems probable that the described "peculiarities" are in fact representative of the more common forms of $D u$ gesia gonocephala s.str. in Europe. Is it possible that Ude (1908) has studied a rather unusual type that is not widely distributed? Since his figure and description have been so widely incorporated into the current literature it may be that current concepts of the species, in its restricted sense, are not representative.

Though many forms and species of the Dugesia gonocephala group have been described in great detail, yet there remains confusion and uncertainty over the interpretation of the natural relationships within this group. It is clear from the present study that many questions concerning the species remain unanswered. Just what are the limits of morphological and karyological variation? What are the geographical ranges of the different forms, and are they partly or wholly reproductively isolated? Elucidation of these problems can only be achieved by further study of diverse populations of this so-called "well-known" species.

\section{ACKNOWLEDGEMENTS}

We thank Ronald A. Gase, Bert Pex and Hilde Veenstra for their help in collecting specimens, and Dr. N. Gourbault (Muséum National d'Histoire Naturelle, Paris) and Profes- sor M. Benazzi (Isituto di Zoologia e Anatomia Comparata, Università di Pisa) for the loan of many slides of comparative material. We are also grateful to Prof. and Mrs. Benazzi for the hospitality shown to Elizabeth de Vries during her study visit to Pisa. Mr. L. A. van der Laan and Mr. J. Zaagman are also thanked for their assistance with the figures.

This paper is derived from the research report submitted by $\mathrm{E}$. J. de Vries in partial fulfillment of the requirements for the degree of Doctorandus (M.Sc.) in Biology at the University of Amsterdam.

\section{REFERENCES}

BALL, I. R., 1970. Freshwater triclads (Turbellaria, Tricladida) from the Oriental region. Zool. J. Linn. Soc., 49: 271-294.

- 1974. A contribution to the phylogeny and biogeography of the freshwater triclads (Platyhelminthes: Turbellaria). In: N. W. RISER \& M. P. MORSE eds., Biology of the Turbellaria: 339-401 (McGraw-Hill, New York).

$\longrightarrow$ 1978. The karyotypes of two Dugesia species from Corfu, Greece (Platyhelminthes, Turbellaria). Bijdr. Dierk., 48: 187-190.

BALl, I. R. \& N. Gourbault, 1975. The morphology, karyology, and taxonomy of a new freshwater planarian of the genus Phagocata from California (Platyhelminthes: Turbellaria). Life Sci. Contr., R. Ont. Mus., 105: $1-19$.

Benuchamp, P. DE, 1936. A propos d'Euplanaria cretica Meixner. Bull. Soc. zool. Fr., 61: 433-440.

_ 1961. Classe des Turbellariés. In: P. P. Grassé ed., Traité de zcologie, 4 (1): 35-212 (Masson et Cie., Paris).

Benazzi, M., 1949. Dati sul differentiamento razziale e specifico nelle planarie. Atti Soc. tosc. Sci. nat., 56B: 43-48.

—, 1955. L'evoluzione della poliploidia nelle planarie appartenenti alla superspecie "Dugesia gonocephala". Atti Accad. naz. Lincei, Rc., Cl. Sc. fis. mat. nat., (8) 18: 527-533.

Benazzi, M. \& G. Benazzi-Lentati, 1976. Animal cytogenetics, 1. Platyhelminthes: 1-182 (Gebr. Borntraeger, Berlin \& Stuttgart).

Böhmig, L., 1909. Tricladida. In: A. Brauer ed., Die Süsswasserfauna Deutschlands, 19: $143-176$ (G. Fischer, Jena).

BRomley, H., 1974. Morpho-karyological types of Dugesia (Turbellaria, Tricladida) in Israel and their distribution patterns. Zoologica Scr., 3: 239-242.

DAнM, A. G., 1958. Taxonomy and ecology of five species groups in the family Planariidae (Turbellaria, Tricladida, Paludicola): 1-241 (Nya Litografen, Malmö).

_- 1963. The karyotypes of some freshwater triclads from Europe and Japan. Ark. Zool., 16: 41-67. 1967. A new Dugesia "microspecies" from Ghana belonging to the Dugesia gonocephala group. Ark. Zool., 19: 309-321.

Dugès, A., 1830. Aperçu de quelques observations nouvelles sur les Planaires et plusieurs genres voisins. Annls. Sci. nat., 21: 72-91.

Gourbault, N. \& M. Benazzi, 1979. Une nouvelle espèce ibérique du "groupe Dugesia gonocephala" (Turbellariés, Triclades). Bull. Mus. natn. Hist. nat. Paris, (4) 1: 329-337. 
GrafF, L. voN, 1912-1917. Tricladida. In: Bronn's Klassen und Ordnungen des Thier-Reichs, IV, 1c (Turbellaria), Abt. 2: i-xxxvii, 2601-3369 (C. F. Winter, Leipzig).

Hartog, C. DEN, 1962. De Nederlandse platwormen - Tricladida. Wet. Meded. K. ned. natuurh. Veren., 42: 1-40.

Hyman, L. H., 1939. New species of flatworms from North, Central, and South America. Proc. U.S. natn. Mus., 86: 419-439.

- 1951. North American triclad Turbellaria, XII: Synopsis of the known species of fresh-water planarians of North America. Trans. Am. microsc. Soc., 70: 154-167.

IJIMA, I., 1887. Uber einige Tricladen Europa's. J. Coll. Sci. imp. Univ. Tokyo, 1: 337-358.

Kawakatsu, M., 1971. Problems on the morphological variation and the physiological races of a Japanese freshwater planarian, Dugesia japonica Ichikawa \& Kawakatsu. In: M. KAwAKATsU \& M. IBA eds., A commemorative compilation of scientific papers published on the occasion of the retirement of Professor Hisao Sugino: 43-52 (Osaka Kyôiku University, Osaka).

- 1972. Report on freshwater planarians from South Africa. Bull. Fuji Wom. Coll., (2) 10: 57-79.

Kawakatsu, M., I. OKi, S. Tamura \& H. Sugino, 1976. Studies on the morphology, karyology and taxonomy of the Japanese freshwater planarian Dugesia japonica Ichikawa et Kawakatsu, with a description of a new subspecies Dugesia japonica ryukyuensis subsp. nov. Bull. Fuji Wom. Coll., (2) 14: 81-126.

KenK, R., 1930. Euplanaria cretica Meixner, eine Triklade mit eigentümlichem Drüsenorgan. Zool. Anz., 92: 247. 253.

LEPORI, N. G., 1951. Sulle carratteristiche morfologiche e sulla posizione sistematica della Planaria di Sardegna \& Corsica già ascritta a Dugesia (= Euplanaria) gonocephala (Dugès). Atti Soc. tosc. Sci. nat., 58B: 28-47.

Levan, A., K. Fredga \& A. A. Sandberg, 1964. Nomenclature for centromeric position on chromosomes. Hereditas, 52: 201-220.

Marcus, E., 1953. Turbellaria Tricladida. Explor. Parc natn. Upemba Miss. G. F. de Witte, 21: 1-62.

- 1955. Turbellaria. Explor. Parc. natn. Garamba Miss. H. de Saeger, 3: 1-31.

MeIXNER, J., 1928. Der Genitalapparat der Tricladen und seine Beziehungen zu ihrer allgemeinen Morphologie, Phylogenie, Ökologie und Verbreitung. Z. Morph. Ökol. Tiere. 11: 570-612.

SCHмIDT, O., 1860. Die dendrocoelen Strüdelwürmer aus den Umgebung von Graz. Z. wiss. Zool., 10: 211-233.

SteinmanN, P. \& E. Bresslau, 1913. Die Strüdelwürmer (Turbellaria): i-xi, 1-380 (W. Klinckhardt, Leipzig).

STOPPENBRINK, F., 1905. Der Einfluss herabgesetzter Ernährung auf den histologischen Bau der Süsswassertricladen. Z. wiss. Zool., 79: 496-547.

Tamura, S., T. Yamayoshi, J. OKI, H. Muramaya \& M. KAWAKATSU, 1978. Chromosomes of the animals of Dugesia japonica collected from five localities in the central part of Honshû and Shikoku, Japan. Proc. Jap. Soc. Syst. Zool., 15: 9-18.

UDE, J., 1908. Beiträge zur Anatomie und Histologie der Süsswassertricladen. Z. wiss. Zool., 89: 308-370.

Young, J. O. \& B. M. Young, 1974. The distribution of freshwater triclads (Platyhelminthes; Turbellaria) in Kenya and Tanzania, with ecological observations on a stream-dwelling population. Zool. Anz., 193: 350-361.

Received: 15 July 1980 